\title{
1 Pasting properties of transgenic lines of a commercial bread wheat 2 expressing combinations of HMW glutenin subunit genes
}

3

4

5 Elena Leon ${ }^{\mathrm{a}}$, Racha Aouni ${ }^{\mathrm{b}}$, Fernando Piston ${ }^{\mathrm{a}}$, Peter R. Shewry ${ }^{\mathrm{c}}$, Cristina M. Rosell ${ }^{\mathrm{d}}$, 6 Antonio Martin ${ }^{\mathrm{a}}$, Francisco Barro ${ }^{\mathrm{a}^{*}}$

7

8 a Instituto de Agricultura Sostenible, CSIC, E-14080-Córdoba, Spain

9 b Agrasys, S.L., E-08028 Barcelona, Spain

$10{ }^{\mathrm{c}}$ Rothamsted Research, Harpenden, Hertfordshire AL5 2JQ, UK

11 d Instituto de Agroquímica y Tecnología de Alimentos, CSIC, E-46100-Valencía, Spain

12 * Corresponding author:

13 Francisco Barro

14 Instituto de Agricultura Sostenible, CSIC

15 Alameda del Obispo s/n

16 14080, Córdoba, Spain

17 Telephone: +34957499240

18 Fax: +34957499252

19

e-mail: fbarro@ias.csic.es 


\section{Abstract}

Seven transgenic lines of a commercial wheat (Triticum aestivum L.) cultivar expressing transgenic subunits $1 \mathrm{Ax} 1,1 \mathrm{Dx} 5$ and $1 \mathrm{Dy} 10$, alone or in combination have been developed. Pasting properties were determined in these transgenic lines using a Rapid Visco Analyser (RVA) in order to determine the possible impact of HMW-GS transgene expression on the starch properties. Expression of the HMW-GS transgenes increased the proportions of the corresponding 1Ax, 1Dx and 1Dy subunits affecting significantly the ratios of HMW-GS:LMW-GS and x-type:y-type HMW-GS. Starch granule size distribution varied significantly among all transgenic lines, with the Anza control and transgenic line T616 (expressing subunits 1Ax1 and 1Dy10) showing the highest and the lowest percentage of $\mathrm{B}$ granules, respectively. All transgenic lines increased the water binding capacities (WBC) at $25^{\circ} \mathrm{C}$ and $90^{\circ} \mathrm{C}$. Line T606 (expressing subunits 1Ax1 and 1Dx5) and line T590 (expressing subunit 1Dy10) showed the lowest and the highest values for peak viscosity, respectively. Notably, lines expressing only transgenic x-type subunits (T580, T581 and T606), with high ratios of x-type:y-type HMW-GS, had low peak viscosities, final viscosities and breakdown viscosities. Line T590 had the highest breakdown viscosity while lines T606 and T581 had the lowest.

Keywords: Cereal; breeding; HMW-GS; Pasting; GM; wheat; 
42 Abbreviations

43 AACC American Association of Cereal Chemists

$44 \quad$ ER $\quad$ Endoplasmic Reticulum

45 HMW-GS High Molecular Weight Glutenin Subunit

46 ICC International Association for Cereal Science and Technology

47 LMW-GS Low Molecular Weight Glutenin Subunit

48 LSD Least Significant Difference

49 RVA Rapid Visco Analyser

50 SDS-PAGE Sodium Dodecyl Sulfate PolyAcrylamide Gel Electrophoresis

$51 \quad$ WBC Water Binding Capacities

52

53

54

55 


\section{Introduction}

Cereals are of enormous importance to humankind for food, livestock feed and industrial raw materials. Starch and proteins are major components of the mature wheat (Triticum aestivum L.) grain and are responsible for the ability to make many wheatbased food products. Starch accounts for about $60-70 \%$ of the wheat grain dry matter. Starch is deposited in partially crystalline granules that vary in morphology and structure between and within plant species. Starch owes much of its functionality in foods to the characteristics of the two constituent glucose polymers, amylose and amylopectin, and to the physical organization of these macromolecules into the granular structure (Annison and Topping, 1994). Amylopectin with its multiple branched chains of (1-4)- $\alpha$-glucans interlinked by (1-6)- $\alpha$-linkages is the major component of starch, with the unbranched amylose accounting for the minor fraction. These components are synthesized in amyloplasts in the form of distinct granules. Typically wheat starch is recognized as having at least two different starch granule populations of distinct size and shape (Parker, 1985; Peng et al., 1999). The 'A' granules are large and lenticular, while the ' $\mathrm{B}$ ' are small and spherical. Variation in starch functionality and pasting properties has been related to differences in starch granule size distribution and composition (Ao and Jane, 2007; Dengate and Meredith, 1984). The B granules have higher contents of lipids than the A granules (Ao and Jane, 2007; Soulaka and Morrison, 1985). Early studies showed that the A and B granules had similar proportions of amylose (about 20-26\%) (Evers et al., 1974; Meredith et al., 1981) although a more recent study reported A granules to have higher amylose contents than B granules (Ao and Jane, 2007). Starch granules are insoluble in water below $50^{\circ} \mathrm{C}$ and when they are heated in water beyond a critical temperature, the granules absorb a large amount of 
water and swell to many times their original size. Over a critical temperature range, the starch granules undergo an irreversible process known as gelatinization and loss their granular organization. Numerous studies have indicated that the relationships between the amylose and amylopectin contents and molecular structures of starches, and their water absorption and pasting properties, are complex and vary considerably amongst starches from different genotypes (Dang and Copeland, 2004; Dengate and Meredith, 1984; Peterson and Fulcher, 2001). Differences between the structures and properties of starches among different cereals, and between mutant types of starch which occur within cereal species, also affect their functionality in different food systems, including wheat starch in breadmaking (Stone and Morell, 2009).

The protein fraction of wheat grain represents about $8-15 \%$ of the whole grain dry matter. The prolamin storage proteins, which correspond to the gluten proteins, are the most important protein fraction present in the wheat grain. The gluten proteins are synthesized on the rough endoplasmic reticulum (ER), co-translationally transported into the lumen of the ER and subsequently either deposited within protein bodies derived directly from the ER or transported to the vacuole to form a second population of protein bodies (Kumamaru et al., 2007; Tosi et al., 2009). When the cells of the starchy endosperm dry and die during the later stages of grain maturation, the protein deposits fuse to form a proteinaceous network in each endosperm cell. These networks are brought together when flour is mixed with water to form a continuous network in the dough. The high molecular weight glutenin subunits (HMW-GS) of wheat play an important role in determining the functional properties of this protein network and hence of wheat dough. Allelic differences in the HMW-GS composition result in effects on the structures and properties of the glutenin polymers and thus on breadmaking 
quality (Payne, 1987; Shewry et al., 2003a). Therefore, genes for HMW-GS, in particular those encoding subunits $1 \mathrm{Ax} 1,1 \mathrm{Dx} 5$ and 1Dy10, have been identified as targets for expression in transgenic wheat (Altpeter et al., 1996; Barro et al., 1997; Blechl and Anderson, 1996; Blechl et al., 2007; León et al., 2009a) to develop cultivars with new HMW-GS combinations and hence with improved or novel functional properties. As the expression of these HMW-GS transgenes in transgenic wheat alters the proportions of glutenins to gliadins, the ratio of polymeric to monomeric gluten proteins, the ratio of HMW-GS to LMW-GS and the contents of individual subunits, they also affect the size, composition and functional properties of the glutenin polymers formed in each line. Consequently, differential effects of transgenes encoding HMWGS 1Ax1, 1Dx5 and 1Dy10 on gluten properties have been reported (Barro et al., 2003a; 2003b; Blechl et al., 2007; Darlington et al., 2003; León et al., 2009a). The presence of different HMW-GS can also affect the interactions of the gluten matrix with starch and hence the pasting properties of wheat. In fact, differential effects on peak viscosity between subunits from the Glu-1B locus, and between subunits from Glu-1D locus have been reported (Batey, 2000).

We have developed a set of seven transgenic lines expressing HMW-GS 1Ax1, 1Dx5 and 1Dy10 of a commercial wheat cultivar Anza, which endogenous HMW-GS composition is $1 \mathrm{Bx} 7 *, 1 \mathrm{By} 8,1 \mathrm{Dx} 2$ and $1 \mathrm{Dy} 12$. Three lines were single transformants while in the other four lines the HMW-GS genes were combined by conventional crossing. This set of lines represents an excellent background in which to evaluate the effects of HMW-GS transgene combinations on the functional properties including the pasting properties of wheat flour. 


\section{Materials and Methods}

129

130

131

132

133

134

135

136

137

138

139

140

141

142

\subsection{Plant material}

Seven transgenic lines expressing the transgenes encoding HMW-GS 1Dx5, $1 \mathrm{Ax} 1$ and 1Dy10, single or in combination, were used in this work. Lines T580, T581 and T590 were obtained by genetic transformation as described by León et al. (2009a) while lines T606, T616, T617 and T618 were obtained by conventional crossing using former lines as parents (León et al., 2009b). The control line was the bread wheat cv Anza as the parent of the transgenic lines, which which endogenous HMW-GS composition is $1 \mathrm{Bx} 7 *, 1 \mathrm{By} 8,1 \mathrm{Dx} 2$ and $1 \mathrm{Dy} 12$. Lines were analysed over two years, using a randomized complete block design with two replicates, as described by Barro et al. (2002).

\subsection{Protein and SDS-PAGE analysis}

The protein content of whole flour was calculated from the Kjeldahl nitrogen content (\% $\mathrm{N}$ x.7) and expressed on a dry matter basis. Seeds were crushed into a fine powder which was used to extract the endosperm storage proteins. Gliadins were extracted in $60 \%(\mathrm{v} / \mathrm{v})$ aqueous ethanol using a rotary shaker for $40 \mathrm{~min}$. Samples were centrifuged at $13000 \mathrm{xg}$ for $5 \mathrm{~min}$ and the supernatant collected. Glutenins were extracted as described by Shewry et al. (1995). For densitometry, glutenins from thirty individual seeds per line and year (60 seeds in total) were separated by SDS-PAGE gels and analysed using a Kodak Image Station 440CF and Kodak 1D Image Analysis Software using the SDS-PAGE Molecular Weight Standards from Bio-Rad as reference. 


\subsection{Starch and amylose determinations}

152 The starch content of whole flour was determined according to standard ICC method no. 123/1 (ICC, 1994). Four samples per genotype and year were used.

Amylose/Amylopectin Assay (Megazyme International Ireland Ltd, Bray, Ireland) according to the manufacturer's recommendations. The Megazyme standard of $64 \%$ amylose content was used as a control. The amylose content was expressed in percentage of starch dry weight. Four different replicates per genotype and year were used.

\subsection{Starch granule size analysis}

Starch granules were isolated from wheat genotypes according to Caballero et al. (2008) using 90 mg of flour. Starch granule size was measured using an Axioskop 2 MOT microscope (Carl Zeiss Vision GmbH, Germany). Four biological replicates per genotype and year were used and, for each sample, fifteen fields were counted.

\subsection{Water binding capacity (WBC)}

The water binding capacity was measured as the amount of water that one gram of material will retain after centrifugation using AACC method 56-30 (AACC, 1999) and also after heating at $90^{\circ} \mathrm{C}$. Briefly, the wheat flour suspension was kept in a water bath at $90^{\circ} \mathrm{C}$ for $10 \mathrm{~min}$. After cooling for one hour, the water binding capacity of the samples was determined using the standard method. 


\subsection{Rapid visco-analysis}

The pasting profiles were obtained using whole flour with a Rapid Visco

175 Analyser (RVA-4, Newport Scientific, Warriewood, Australia ) according to the ICC 176 standard method 162 (ICC, 1996). Two biological replications per year and genotype 177 were analysed.

\section{$178 \quad$ 1.7. Statistics}

Data were analysed using the SPSS version 11.0 statistical software package (SPSS Inc., Chicago, Illinois, USA). Arcsine transformation was carried out on variables expressed as percentages before analysis. The general analysis of variance and the least significant difference (LSD) pairwise comparisons of means were used to determine significant differences. Simple correlations was performed using Statgraphics V.7.1 program (Bitstream, Cambridge, MN).

\section{Results and discussion}

\subsection{Protein properties of transgenic lines}

Table 1 compares the characteristics of the transgenic lines with the control line Anza, which expresses four endogenous HMW-GS: 1Bx7*+1By8 and 1Dx2+1Dy12. 190 Consequently, the total number of HMW-GS ranged from four for control line Anza to seven for line T618. Although transformation and further crossing of the transgenic lines resulted in lines containing increasing numbers of HMW-GS, this did not have a significant effect on the total flour protein content compared to the Anza control (Table 1). The expression of transgenic subunits significantly affected the proportions of the 
two major glutenin protein fractions in the endosperm of wheat lines. Thus, the HMW-

196 GS:LMW-GS ratio and proportions of HMW-GS in the glutenin fraction were increased

197 in all lines with respect to the Anza control, with the increases being significant for five

198 of the lines but not for lines T590 and T606, expressing the 1Dy10, and the $1 \mathrm{Ax} 1$ and

199 1Dx5 transgenes, respectively (Table 1). Notably, this increase was greatest in line

200 T618, which expressed all three HMW-GS transgenes, and was associated with a correspondingly lower proportion of LMW-GS. The expression of the HMW-GS transgenes also resulted in increased proportions of the corresponding $1 \mathrm{Ax}, 1 \mathrm{Dx}$ and 1Dy subunits. However, differential effects on the proportions of individual endogenous HMW-GS were also observed. The proportion of subunit 1 By8 was decreased in most lines but not in line T581, expressing subunit $1 \mathrm{Dx} 5$. In contrast, the proportion of subunit 1Bx7* was reduced significantly in two lines, (T606 and T616) that both expressed the subunit $1 \mathrm{Ax} 1$ transgene. The ratio of x-type:y-type HMW-GS varied significantly with the different combinations of transgenes. In particular, the expression of x-type subunits (lines T580, T581 and T606) significantly increased the ratio of xtype:y-type with respect to the Anza control, whereas the expression of y-type subunits (line T590) decreased this ratio (Table 1). However, when one x-type and one y-type subunit were expressed together (lines T616 and T617), the x-type:y-type ratios were more balanced and similar to that of the Anza control. Again, the expression of two xtype and one y-type subunits in line T618 resulted in a higher $\mathrm{x}$-type:y-type ratio than in the T616 and T617 lines and equal to that of the line expressing only $1 \mathrm{Dx} 5$. 


\subsection{Starch and Pasting properties of transgenic lines}

The starch and amylose contents did not show differences among the transgenic lines (Table 2). In particular, the amylose contents of the lines agreed with those reported for hexaploid wheat (Soulaka and Morrison, 1985). The starch granule size distribution for the transgenic lines reported in this work is given in Table 2. A cut-off diameter of $10 \mu \mathrm{m}$ for the A and B granule size classes was selected based on results reported by other researches (Dengate and Meredith, 1984; Peterson and Fulcher, 2001; Salman et al., 2009). Notably, the B granules made up the major portion of the total percentage of granules. Even though starch granule size varied only within a $3.0 \%$ range, these differences were statistically significant (Table 2). The control line Anza showed the highest percentages of B granules, and lines T616 (expressing subunits $1 \mathrm{Ax} 1$ and 1Dy10) and T606 (expressing subunits $1 \mathrm{Ax} 1$ and 1Dx5) the lowest . It has been calculated that the total surface of the B granules is about three times greater than that of the A granules and suggested that this contributes to endosperm cohesiveness and strength (Konopka et al., 2005). Starch granule size distribution has been related to the pasting and mixing properties of wheat (Dengate and Meredith, 1984; Park et al., 2009; Peterson and Fulcher, 2001). However, other researchers suggest that the composition and structure of the starch rather than the size of the starch granules determine the pasting properties of wheat (Ao and Jane, 2007).

Water-binding capacity was determined in all transgenic lines at $25^{\circ} \mathrm{C}$ and also after heating at $90^{\circ} \mathrm{C}$ (Table 2), in order to determine the water uptake of the starch granules before and after gelatinization. The expression of HMW-GS transgenes increased the WBC of all transgenic lines at both $25^{\circ} \mathrm{C}$ and $90^{\circ} \mathrm{C}$ in comparison to Anza control. Lines 
T606 (expressing subunits 1Ax1 and 1Dx5) and T616 (expressing subunits 1Ax1 and 1Dy10) showed the highest $\mathrm{WBC}$ at $25^{\circ} \mathrm{C}$ and $90^{\circ} \mathrm{C}$, respectively (Table 2).

The pasting properties of transgenic lines expressing different combinations of HMW-GS transgenes were determined using the Rapid Visco Analyser (RVA). The RVA is an effective instrument for determining the viscous properties of flour as a function of processing temperature and stirring rate, and for relating functionality to structural properties (Collar et al., 2006). However, these relationships are complex, and the results influenced by factors include genetics, processing, and environmental conditions (Batey et al., 2001; Becker et al., 2001). In the work described here, the transgenic lines are derived from the same genetic background. This allows the comparative study of the effect of different combinations of HMW-GS transgenes on the pasting properties of wheat flour (Table 3). When flour is tested in the RVA, it is subjected to a heat-hold-cool cooking cycle which gives a pasting curve for the sample

(Figure 1). The most important parameters measured include pasting temperature, peak time, peak viscosity, breakdown, final viscosity and setback (Table 3). The pasting temperature gives an indication of the minimum temperature required to cook a given sample, and also indicates energy costs. Though the pasting temperatures of the lines studied in this work ranged from $82.2^{\circ} \mathrm{C}$ to $86.8^{\circ} \mathrm{C}$, these differences were not statistically significant (Table 3), suggesting that all of the lines had comparable gelatinization properties. After reaching the pasting temperature, the temperature is increased further and peak viscosity is reached (Figure 1). At this point, there is an equilibrium between starch granule swelling and rupture, with amylose leaching out into solution. Line T606 (expressing subunits 1Ax1 and 1Dx5) showed the lowest value for the peak time, while there were no significant differences among the other lines 
266 (Table 3). Line T606 also showed the lowest value for peak viscosity and line T590

267 (expressing subunit 1Dy10) together with Anza the highest. The peak viscosity is 268 related to the water uptake capacity of the starch, and it is often correlated with final 269 product quality. In fact, high viscosities during pasting and low viscosities after the 270 holding period at $95^{\circ} \mathrm{C}$ of wheat dough slurries are considered valuable predictors of 271 bread firming behaviour during storage (Collar, 2003). The three lines expressing only transgenic x-type subunits (T580, T581 and T606), with high x-type:y-type ratios 273 (Table 1), also had low peak viscosities. The decrease in peak viscosity has been associated with a lower degree of swelling of the starch granules and also lower starch contents (Symons and Brennan, 2004). However, no significant correlation was found between peak viscosity and the starch content or granule size distribution (Table 3, 4).

During the holding period at constant high temperature, a breakdown in viscosity to a holding strength or trough, takes place (Figure 1). The transgenic lines showed significant differences in the breakdown viscosities (Table 3). Line T590 (expressing subunit 1Dy10) had the highest breakdown viscosity while line T606 had the lowest (Table 3). Line T590 expresses the transgenic HMW-GS 1Dy10 while line T606 expresses transgenic HMW-GS 1Ax1 and 1Dx5 (Table 1).

The breakdown in viscosity is caused by rupture of the swollen granules (Rani and Bhattacharya, 1995). The lower breakdown viscosity for lines T606 and T581 may therefore be related to a decrease in the rate of rupturing of the starch granules during RVA processing. This parameter has been linked to the cooking or hot stability or the easiness of cooking the starch (Rojas et al., 1999), thus, differences observed in this parameter revealed different heating stability of the starch granules of different lines. 
The last phase in the pasting curve (Figure 1) is the setback region, and corresponds to the gelling process of the starch, in which the amylose chains are prompted to recrystalize, yielding the formation of a gel structure. In the cereal slurries, low values of setback indicate low rates of starch retrogradation and low syneresis (Rojas et al., 1999). Setback is measured as the difference between final viscosity and holding strength or trough, while the final viscosity indicates the ability of the flour to form a viscous paste after cooking and cooling. Lines T590 and Anza control showed the highest values for final viscosity (Table 3) while line T606 had the lowest. Notably, lines T606, T580 and T581, which express only transgenic x-type subunits, with high xtype:y-type ratios, showed lower values for final viscosity than the other lines (Table $3)$.

The lines expressing only transgenic x-type subunits had low peak viscosities and final viscosities. This is particularly marked for line T606 which expresses the 1Ax1 and 1Dx5 HMW-GS transgenes. In addition, the decrease in the breakdown viscosity was also less for line T606 (Figure 1). Lower values for pasting viscosities are an indication of a reduction of the available starch for gelatinization (Collar et al., 2006). This reduction is unlikely to be due to a reduction in the starch content of this line as all of the lines had similar levels of starch (Table 2).

\section{General discussion}

We have developed a series of seven transgenic lines of a commercial wheat cultivar expressing single, double or, in the case of line T618, triple combinations of the HMWGS 1Ax1, 1Dx5 and 1Dy10 transgenes. The expression of the HMW-GS transgenes 
312 increased the proportions of the corresponding 1Ax, 1Dx and 1Dy subunits, and this is expected to affect the size and structure of the different glutenin polymers formed in each transgenic line. Notably, the expression of transgenic x-type subunits (lines T580, T581 and T606) increased the ratio of x-type:y-type HMW-GS in comparison to that of Anza control and lines which expressed transgenic subunit 1Dy10 alone. All transgenic lines had higher HMW-GS:LMW-GS ratios than the Anza control, except lines T590 and T606, which didn't show significant differences in comparison to Anza. Although all of the transgenic lines had comparable levels of starch and amylose, they had lower proportions of B granules than the Anza control. It is difficult to establish the cause of these differences as the A and B granules differ in their time of biogenesis during grain filling. The A granules start to form at about 4-5 days after anthesis and continue until physiological maturity. On the other hand, B granules are initiated at 10-12 days after anthesis and continue to accumulate until about 35 days after anthesis (Bechtel et al., 1990; Parker, 1985). However, the proportions of A granules correlated well with WBC at $25^{\circ} \mathrm{C}$ as lines with higher WBC at $25^{\circ} \mathrm{C}$ had higher contents of A granules. Although the lines studied in this work did not significantly differ in protein content, there were clear differences in the glutenin subunit and polymer composition of in the transgenic lines in comparison with the Anza control. These changes in protein composition appeared to be associated with changes in protein:starch interactions and in turn, in the pasting properties of the transgenic wheat lines. Notably, peak viscosity, final viscosity, and breakdown viscosity were lower in transgenic lines expressing only x-type subunits (lines T580, T581 and T606). In contrast, line T590 (expressing subunit 1Dy10) had the lowest ratio of x-type:y-type HMW-GS and also had the highest values for peak viscosity, final viscosity and breakdown viscosity. Our results also showed a negative correlation between $\mathrm{WBC}$ at $25^{\circ} \mathrm{C}$ and peak viscosity, final viscosity and setback (Table 
337 4). Flour from line T606 (expressing subunits $1 \mathrm{Ax} 1$ and $1 \mathrm{Dx} 5$ ) had a higher water binding capacity at $25^{\circ} \mathrm{C}$ than the other lines. However, at $90^{\circ} \mathrm{C}$ line $\mathrm{T} 616$ (expressing subunits $1 \mathrm{Ax} 1$ and 1Dy10) showed the highest value for WBC. This result clearly indicates that the effects of the expression of the HMW-GS on the gluten matrix significantly modifies the WBC and influences the pasting properties of transgenic 342 lines.

It is clear that water plays an important part in wheat flour processing, with gluten, starch and cell wall polysaccharides all competing for water absorption, ultimately defining the technological functionality of the wheat flour (Rosell and Collar, 2009).The HMW-GS present in transgenic lines differ in their number and distributions of cysteine residues and these transgenic lines would therefore be expected to differ in the extent and pattern of cross-linking of the gluten matrix. In particular, HMW-GS 1Dx5 has an additional cysteine residue in the repetitive domain, and it has been suggested to provide an additional site for inter-chain bonds between HMW-GS (Shewry et al., 2003b). The extent of cross-linking of the gluten matrix would in turn be expected to affect its WBC and hence its competition for water with starch and other components and flour pasting properties. Results of WBC support this explanation as all transgenic lines had higher $\mathrm{WBC}$ at $25^{\circ} \mathrm{C}$ and $90^{\circ} \mathrm{C}$ than Anza control. Notably, line T606 (expressing subunits $1 \mathrm{Ax} 1$ and $1 \mathrm{Dx} 5$ ) had significantly higher $\mathrm{WBC}$ at $25^{\circ} \mathrm{C}$ than the rest of lines. The $\mathrm{WBC}$ at $25^{\circ} \mathrm{C}$ was also positively correlated with the content of $\mathrm{A}$ granules and negatively correlated with the content of B granules, peak viscosity, final viscosity, and setback (Table 4). Finally, all transgenic lines had low contents of B granules which have been reported to contain higher proportions of lipids (Whattam and 
361 levels of starch lipids are thought to have a negative impact on granule swelling due to

362 the inhibition of amylose mobility (Morrison et al., 1993). The results agree with our 363 findings, since the transgenic lines had lower contents of B granules and higher WBC at $36425^{\circ} \mathrm{C}$.

In conclusion, differences in the pasting properties of bread wheat are associated with the expression of single and multiple HMW-GS transgenes. Lines expressing only transgenic x-type subunits (T580, T581 and T606), with high ratios of x-type:y-type HMW-GS, had differences in pasting properties with reduced peak and final viscosities, and breakdown viscosity. In contrast, line T590 (expressing subunit 1Dy10), with the lowest ratio of x-type:y-type HMW-GS, showed the highest values for peak viscosity, final viscosity and breakdown viscosity.

\section{Acknowledgements}

The authors acknowledge funding by the Spanish C.I.C.Y.T. (project AGL2007-65685C02- 01). Rothamsted Research receives grant-aided support from the Biotechnology and Biological Sciences Research Council (BBSRC) of the UK. The technical assistance of Ana García and Azahara Vida are also acknowledged.

\section{References}

380 AACC, 1999. Method 56-30-Water hydration capacity of protein materials, reappr. Approved Methods of the American Association of Cereal Chemists. The Association, St Paul, MN, 2000. 
Altpeter, F., Vasil, V., Srivastava, V., Vasil, I.K., 1996. Integration and expression of the high molecular weight glutenin subunit 1Ax1 gene into wheat. Nature Biotechnology 14, 1155-1159.

Annison, G., Topping, D.L., 1994. Nutritional role of resistant starch: Chemical structure versus physiological function. Annual Review of Nutrition 14, 297-320.

Ao, Z., Jane, J.L., 2007. Characterization and modeling of the A- and B-granule starches of wheat, triticale, and barley. Carbohydrate Polymers 67, 46-55.

Baldwin, P.M., 2001. Starch granule-associated proteins and polypeptides: A review. Starch-Starke 53, 475-503.

Barro, F., Barcelo, P., Lazzeri, P.A., Shewry, P.R., Ballesteros, J., Martin, A., 2003a. Functional properties of flours from field grown transgenic wheat lines expressing the HMW subunit 1Ax1 and 1Dx5 genes. Molecular Breeding 12, 223-229.

Barro, F., Barcelo, P., Lazzeri, P. A., Shewry, P. R., Martin, A., Ballesteros, J., 2003b. Functional properties and agronomic performance of transgenic tritordeum expressing high molecular weight glutenin subunit genes 1Ax1 and 1Dx5. Journal of Cereal Science 37, 65-70.

Barro, F., Barcelo, P., Lazzeri, P.A., Shewry, P.R., Martín, A., Ballesteros, J., 2002. Field evaluation and agronomic performance of transgenic wheat. Theoretical and Applied Genetics 105, 980-984.

Barro, F., Rooke, L., Bekes, F., Gras, P., Tatham, A.S., Fido, R., Lazzeri, P.A., Shewry, P.R., Barcelo, P., 1997. Transformation of wheat with high molecular weight 

subunit genes results in improved functional properties. Nature Biotechnology 15, 1295-1299.

Batey, I.L., 2000. Interactions of starch with glutens having different glutenin sub-units. In: Shewry, P.R., Tatham, A.S. (Eds.), Wheat gluten. Royal Society of Chemistry, Great Britain, pp 499-502.

Batey, I.L., Hayden, M.J., Cai, S., Sharp, P.J., Cornish, G.B., Morell, M.K., Appels, R., 2001. Genetic mapping of commercially significant starch characteristics in wheat crosses. Australian Journal of Agricultural Research 52, 1287-1296.

Bechtel, D.B., Zayas, I., Kaleikau, L., Pomeranz, Y., 1990. Size-distribution of wheatstarch granules during endosperm development. Cereal Chemistry 67, 59-63.

Becker, A., Hill, S.E., Mitchell, J.R., 2001. Milling - A further parameter affecting the rapid visco analyser (RVA) profile. Cereal Chemistry 78, 166-172.

Blechl, A., Anderson, O.D., 1996. Expression of a novel high-molecular-weight glutenin subunit gene in transgenic wheat. Nature Biotechnology 14, 875-879.

Blechl, A., Lin, J., Nguyen, S., Chan, R., Anderson, O.D., Dupont, F.M., 2007. Transgenic wheats with elevated levels of Dx5 and/or Dy10 high-molecular-weight glutenin subunits yield doughs with increased mixing strength and tolerance. Journal of Cereal Science 45, 172-183.

Caballero, L., Bancel, E., Debiton, C., Branlard, G., 2008. Granule-bond starch synthase (GBSS) diversity of ancient wheat and related species. Plant Breeding 127, 548553. 
425 Collar, C., 2003. Significance of viscosity profile of pasted and gelled formulated wheat doughs on bread staling. European Food Research and Technology 216, 505-513.

427 Collar, C., Santos, E., Rosell, C.M., 2006. Significance of dietary fiber on the 428 viscometric pattern of pasted and gelled flour-fiber blends. Cereal Chemistry 83, $370-376$.

Dang, J. M. C., Copeland, L., 2004. Genotype and environmental influences on pasting properties of rice flour. Cereal Chemistry 81, 486-489.

Darlington, H., Fido, R., Tatham, A.S., Jones, H., Salmon, S.E., Shewry, P.R., 2003. Milling and baking properties of field grown wheat expressing HMW subunit

Dengate, H. N., Meredith, P., 1984. Inherent variation in wheat-starch pasting due to transgenes. Journal of Cereal Science 38, 301-306.

Evers, A.D., Greenwoo, C.T., Muir, D.D., Venables, C., 1974. Studies on biosynthesis of starch granules. Part 8. A Comparison of properties of small and large granules

ICC, 1994. Determination of starch sontent by hydrochloric acid dissolution. International Association for Cereal Science and Technology. Method No. 123/1.

ICC, 1996. Rapid pasting pethod using the Newport rapid visco analyser. International Association for Cereal Science and Technology. Method No. 162.

Konopka, W., Rotkiewicz, D., Tanska, M., 2005. Wheat endosperm hardness. Part II. Relationships to content and composition of flour lipids. European Food Research and Technology 220, 20-24. 
447 Kumamaru, T., Ogawa, M., Satoh, H., Okita, T.W., 2007. Protein body biogenesis in cereal endosperms. Plant Cell Monographs 8, 141-158.

León, E., Marín, S., Giménez, M.J., Piston, F., Rodríguez-Quijano, M., Shewry, P.R., Barro, F., 2009a. Mixing properties and dough functionality of transgenic lines of a commercial wheat cultivar expressing the 1Ax1, 1Dx5 and 1Dy10 HMW glutenin subunit genes. Journal of Cereal Science 49, 148-156.

León, E., Aouni, R., Piston, F., Rodríguez-Quijano, M., Shewry, P.R., Martín, A., Barro, F., 2009b. Stacking HMW-GS transgenes in bread wheat: Combining subunit 1Dy10 gives improved mixing properties and dough functionality. Journal of Cereal Science. doi:10.1016/j.jcs.2009.09.001

Meredith, P., 1981. Large and small starch granules in wheat - are they really different. Starch - Stärke 33, 40-44.

Morrison, W.R., Tester, R.F., Snape, C.E., Law, R., Gidley, M.J., 1993. Swelling and gelatinization of cereal starches .4. Some effects of lipid-complexed amylose and free amylose in waxy and normal barley starches. Cereal Chemistry 70, 385-391.

Park, S.H., Wilson, J.D., Seabourn, B.W., 2009. Starch granule size distribution of hard red winter and hard red spring wheat: Its effects on mixing and breadmaking quality. Journal of Cereal Science 49, 98-105.

Parker, M.L., 1985. The relationship between A-type and B-type starch granules in the developing endosperm of wheat. Journal of Cereal Science 3, 271-278.

Payne, P.I., 1987. Genetics of wheat storage proteins and the effect of allelic variation on bread-making quality. Annual Review of Plant Physiology 38, 141-153. 
Peng, M., Gao, M., Abdel-Aal, E.S.M., Hucl, P., Chibbar, R.N., 1999. Separation and characterization of A- and B-type starch granules in wheat endosperm. Cereal Chemistry 76, 375-379.

Peterson, D.G., Fulcher, R.G., 2001. Variation in Minnesota HRS wheats: starch granule size distribution. Food Research International 34, 357-363.

Rani, M.R.S., Bhattacharya, K.R., 1995. Microscopy of rice starch granules during cooking. Starch - Stärke 47, 334-337.

Rojas, J. A., Rosell, C. M., Benedito, C., 1999. Pasting properties of different wheat flour-hydrocolloid systems. Food Hydrocolloids 13, 27-33.

Rosell, C. M., Collar, C., 2009. Effect of temperature and consistency on wheat dough performance. International Journal of Food Science and Technology 44, 493-502.

Salman, H., Blazek, J., Lopez-Rubio, A., Gilbert, E. P., Hanley, T., Copeland, L., 2009. Structure-function relationships in A and B granules from wheat starches of similar amylose content. Carbohydrate Polymers 75, 420-427.

Shewry, P.R., Halford, N.G., Lafiandra, D., 2003a. The genetics of wheat gluten proteins. Advances in Genetics 49, 111-184

Shewry, P.R., Halford, N.G., Tatham, A.S., Popineau, Y., Lafiandra, D., Belton, P.S., 2003b. The high molecular weight subunits of wheat glutenin and their role in determining wheat processing properties. Advances in Food and Nutrition Research 45, 219-302.

Shewry, P.R., Tatham, A.S., Fido, R.J., 1995. Separation of plant proteins by electrophoresis. In: Jones, H. (Eds.), Methods in Molecular Biology: Plant Gene 

422.

493

494

495

496

497

498

499

500

501

502

503

504

505

506

Soulaka, A.B., Morrison, W.R., 1985. The amylose and lipid contents, dimensions, and gelatinization characteristics of some wheat starches and their A-granule and Bgranule fractions. Journal of the Science of Food and Agriculture 36, 709-718.

Stone, B.A., Morell, M.K., 2009. Carbohydrates. In: Khan, K., Shewry, P.R. (Eds.), Wheat: Chemistry and Technology, fourth ed. American Association of Cereal Chemists, St. Paul, Minnesota, pp. 299-362.

Symons, L. J., Brennan, C. S., 2004. The effect of barley beta-glucan fiber fractions on starch gelatinization and pasting characteristics. Journal of Food Science 69, 257261.

Tosi, P., Parker, M., Gritsch, C. S., Carzaniga, R., Martin, B., Shewry, P. R., 2009. Trafficking of storage proteins in developing grain of wheat. Journal of Experimental Botany 60, 979-991.

Whattam, J., Cornell, H.J., 1991. Distribution and composition of the lipids in starch fractions from wheat-flour. Starch - Stärke 43, 152-156. 
Table 1. Protein properties of transgenic lines.

\begin{tabular}{|c|c|c|c|c|c|c|c|c|c|c|}
\hline \multirow[b]{2}{*}{ Line } & \multirow[b]{2}{*}{$\begin{array}{l}\text { Transgenic } \\
\text { HMW-GS }\end{array}$} & \multirow[b]{2}{*}{$\begin{array}{l}\text { Total } \\
\text { protein } \\
(\mathrm{N} \text { x 5.7) }\end{array}$} & \multicolumn{8}{|c|}{ SDS PAGE } \\
\hline & & & $\begin{array}{l}\text { HMW/ } \\
\text { LMW }\end{array}$ & $\mathrm{x} / \mathrm{y}$ & $\begin{array}{l}\text { HMW } \\
\% \\
\text { glutenin }\end{array}$ & $\begin{array}{l}\text { Ax } \\
\% \\
\text { glutenin }\end{array}$ & $\begin{array}{l}\text { Bx } \\
\% \\
\text { glutenin }\end{array}$ & $\begin{array}{l}\text { By } \\
\% \\
\text { glutenin }\end{array}$ & $\begin{array}{l}\text { Dx } \\
\% \\
\text { glutenin }\end{array}$ & $\begin{array}{l}\text { Dy } \\
\% \\
\text { glutenin }\end{array}$ \\
\hline Anza & NA & $12.0 \mathrm{a}$ & $0.39 \mathrm{~d}$ & $1.41 \mathrm{e}$ & $27.8 \mathrm{c}$ & NA & 8.45 bc & $5.03 \mathrm{a}$ & $7.71 \mathrm{~d}$ & $6.56 \mathrm{c}$ \\
\hline T580 & 1 & $13.3 \mathrm{a}$ & $0.59 \mathrm{bc}$ & $2.69 \mathrm{~b}$ & $36.1 \mathrm{~b}$ & $10.50 \mathrm{a}$ & $7.84 \mathrm{bc}$ & $4.07 \mathrm{~b}$ & $7.34 \mathrm{~d}$ & $5.71 \mathrm{c}$ \\
\hline T581 & 5 & $13.2 \mathrm{a}$ & $0.67 \mathrm{ab}$ & $2.21 \mathrm{c}$ & $38.8 \mathrm{~b}$ & NA & 9.39 a & $5.37 \mathrm{a}$ & $17.36 \mathrm{a}$ & $6.72 \mathrm{c}$ \\
\hline T590 & 10 & $12.5 \mathrm{a}$ & $0.44 \mathrm{~d}$ & $1.03 \mathrm{f}$ & $30.6 \mathrm{c}$ & NA & $8.69 \mathrm{ab}$ & $3.90 \mathrm{~b}$ & $6.82 \mathrm{~d}$ & $11.17 \mathrm{a}$ \\
\hline T606 & 1,5 & $13.3 \mathrm{a}$ & $0.45 \mathrm{~d}$ & $3.72 \mathrm{a}$ & $31.0 \mathrm{c}$ & $6.86 \mathrm{c}$ & $5.41 \mathrm{e}$ & $2.82 \mathrm{c}$ & $12.01 \mathrm{c}$ & $3.92 \mathrm{~d}$ \\
\hline T616 & 1,10 & $12.7 \mathrm{a}$ & 0.56 с & $1.60 \mathrm{~d}$ & $35.8 \mathrm{~b}$ & $8.55 \mathrm{~b}$ & $6.83 \mathrm{~d}$ & $4.03 \mathrm{~b}$ & $6.52 \mathrm{~d}$ & $9.84 \mathrm{~b}$ \\
\hline T617 & 5,10 & $12.4 \mathrm{a}$ & $0.61 \mathrm{bc}$ & $1.61 \mathrm{~d}$ & $37.6 \mathrm{~b}$ & NA & $8.29 \mathrm{bc}$ & $3.78 \mathrm{~b}$ & $14.71 \mathrm{~b}$ & $10.81 \mathrm{a}$ \\
\hline T618 & $1,5,10$ & $12.0 \mathrm{a}$ & $0.74 \mathrm{a}$ & $2.21 \mathrm{c}$ & $42.3 \mathrm{a}$ & $9.05 \mathrm{~b}$ & $7.66 \mathrm{~cd}$ & $2.84 \mathrm{c}$ & 12.36 c & $10.55 \mathrm{ab}$ \\
\hline
\end{tabular}

NA - Not applicable. Values within the same column followed by the same letter are not significantly different $(P<0.05)$. All lines have the endogenous HMW-GS 1Bx7*, 1By8, 1Dx2 and 1Dy12. 
Table 2. Starch content and composition and water binding capacity (WBC) properties of transgenic lines

\begin{tabular}{|c|c|c|c|c|c|c|c|}
\hline \multirow[b]{2}{*}{ Line } & \multirow[b]{2}{*}{$\begin{array}{l}\text { Transgenic } \\
\text { HMW-GS }\end{array}$} & \multirow[b]{2}{*}{$\begin{array}{l}\text { Starch } \\
(\%)\end{array}$} & \multirow[b]{2}{*}{$\begin{array}{l}\text { Amylose } \\
\text { (\%) }\end{array}$} & \multicolumn{2}{|c|}{$\begin{array}{l}\text { Granule size } \\
\text { distribution (\%) }\end{array}$} & \multicolumn{2}{|c|}{ WBC ( $\mathrm{g} \mathrm{H}_{2} \mathrm{O} / \mathrm{g}$ flour) } \\
\hline & & & & A & B & $25\left({ }^{\circ} \mathrm{C}\right)$ & $90\left({ }^{\circ} \mathrm{C}\right)$ \\
\hline Anza & NA & $62.2 \mathrm{a}$ & $25.8 \mathrm{a}$ & $3.9 \mathrm{~d}$ & $96.1 \mathrm{a}$ & $0.760 \mathrm{e}$ & $3.192 \mathrm{e}$ \\
\hline T580 & 1 & $60.0 \mathrm{a}$ & 27.7 a & $6.1 \mathrm{ab}$ & 93.9 cd & 0.796 c & $3.436 \mathrm{~d}$ \\
\hline T581 & 5 & $57.5 \mathrm{a}$ & $30.0 \mathrm{a}$ & $5.4 \mathrm{bc}$ & 94.5 bc & 0.798 c & $3.744 \mathrm{ab}$ \\
\hline T590 & 10 & 58.6 a & $30.1 \mathrm{a}$ & $4.6 \mathrm{~cd}$ & $95.4 \mathrm{ab}$ & $0.783 \mathrm{~d}$ & $3.590 \mathrm{bcd}$ \\
\hline T606 & 1,5 & 59.5 a & $29.4 \mathrm{a}$ & $6.8 \mathrm{a}$ & $93.2 \mathrm{~d}$ & 0.877 a & $3.510 \mathrm{~cd}$ \\
\hline T616 & 1,10 & 62.9 а & $27.5 \mathrm{a}$ & $7.1 \mathrm{a}$ & $92.9 \mathrm{~d}$ & $0.825 \mathrm{~b}$ & 3.837 a \\
\hline T617 & 5,10 & 62.9 a & $29.4 \mathrm{a}$ & $5.4 \mathrm{bc}$ & 94.6 bc & 0.802 c & 3.695 abc \\
\hline T618 & $1,5,10$ & $62.8 \mathrm{a}$ & $28.4 \mathrm{a}$ & $5.3 \mathrm{bc}$ & 94.7 bc & $0.794 \mathrm{~cd}$ & $3.732 \mathrm{ab}$ \\
\hline
\end{tabular}


Table 3. RVA properties of transgenic lines

\begin{tabular}{|c|c|c|c|c|c|c|c|}
\hline \multirow[b]{2}{*}{ Line } & \multirow[b]{2}{*}{$\begin{array}{l}\text { Transgenic } \\
\text { HMW-GS }\end{array}$} & \multicolumn{6}{|l|}{ RVA } \\
\hline & & $\begin{array}{l}\text { Pasting T. } \\
\left({ }^{\circ} \mathrm{C}\right)\end{array}$ & $\begin{array}{l}\text { Peak time } \\
\text { (min) }\end{array}$ & $\begin{array}{l}\text { Peak viscosity } \\
\text { (cP) }\end{array}$ & $\begin{array}{l}\text { Breakdown } \\
\text { (cP) }\end{array}$ & $\begin{array}{l}\text { Final viscosity } \\
\text { (cP) }\end{array}$ & $\begin{array}{l}\text { Setback } \\
\text { (cP) }\end{array}$ \\
\hline Anza & NA & $85.2 \mathrm{a}$ & $5.75 \mathrm{a}$ & $2054 \mathrm{a}$ & $676 \mathrm{ab}$ & $2701 \mathrm{a}$ & $1322 \mathrm{a}$ \\
\hline Т580 & 1 & 83.3 a & $5.70 \mathrm{a}$ & $1712 \mathrm{~b}$ & 566 bc & $2276 \mathrm{~b}$ & $1130 \mathrm{~cd}$ \\
\hline T581 & 5 & $82.2 \mathrm{a}$ & $5.65 a b$ & 1637 b & 507 cd & $2284 \mathrm{~b}$ & 1153 c \\
\hline T590 & 10 & 83.9 a & 5.72 a & 2103 a & 720 a & 2731 a & $1338 \mathrm{ab}$ \\
\hline T606 & 1,5 & 83.5 a & $5.50 \mathrm{~b}$ & 1289 c & $371 \mathrm{~d}$ & 1871 c & 953 d \\
\hline T616 & 1,10 & 86.8 a & $5.73 \mathrm{a}$ & $1859 a b$ & $653 \mathrm{abc}$ & $2350 \mathrm{ab}$ & 1144 bc \\
\hline T617 & 5,10 & 84.9 a & $5.73 \mathrm{a}$ & 1768 b & 569 bc & $2360 \mathrm{ab}$ & 1162 bc \\
\hline T618 & $1,5,10$ & $85.1 \mathrm{a}$ & $5.73 \mathrm{a}$ & $1938 \mathrm{ab}$ & 632 abc & $2514 \mathrm{ab}$ & 1207 abc \\
\hline
\end{tabular}

NA - Not applicable. Values within the same column followed by the same letter are not significantly different $(P<$ $0.05)$ 
Table 4. Correlation matrix between starch and water binding capacity at $25^{\circ} \mathrm{C}$ (WBC25) and $90^{\circ} \mathrm{C}$ (WBC90) and RVA properties of transgenic lines.

\begin{tabular}{|c|c|c|c|c|c|c|c|c|c|c|}
\hline & WBC25 & WBC90 & $\begin{array}{l}\text { Starch } \\
(\%)\end{array}$ & $\begin{array}{l}\text { Amylose } \\
\text { (\%) }\end{array}$ & A-granules & B-granules & $\begin{array}{l}\text { Peak } \\
\text { viscosity }\end{array}$ & Breakdown & $\begin{array}{l}\text { Final } \\
\text { viscosity }\end{array}$ & Setback \\
\hline WBC25 & 1 & & & & & & & & & \\
\hline WBC90 & 0.3496 & 1 & & & & & & & & \\
\hline Amylose (\%) & 0.2761 & 0.4733 & -0.5873 & 1 & & & & & & \\
\hline A-granules & $0.8561 * *$ & 0.4957 & 0.0401 & 0.1559 & 1 & & & & & \\
\hline B-granules & $-0.8517 * *$ & -0.5065 & -0.0198 & -0.1694 & $-0.9995 * * *$ & 1 & & & & \\
\hline Breakdown & -0.6988 & -0.0892 & 0.3481 & -0.3586 & -0.5420 & 0.5526 & $0.9848 * * *$ & 1 & & \\
\hline Final viscosity & $-0.8482 * *$ & -0.2173 & 0.2173 & -0.2915 & $-0.7914^{*}$ & $0.7977 *$ & $0.9825 * * *$ & $0.9404 * * *$ & 1 & \\
\hline Setback & $-0.8758 * *$ & -0.2738 & 0.1180 & -0.2532 & $-0.8308 * *$ & $0.8347^{* *}$ & $0.9569 * * *$ & $0.9086 * *$ & $0.9923 * * *$ & 1 \\
\hline
\end{tabular}

Correlations indicated by $R^{2}$ values. $* * * P$-value $<0.001$. ** $P$-value $<0.01 . * P$-value $<0.05$. 


\section{Figure legends}

Figure 1. Plots of pasting and gelling of whole flour doughs recorded with the Rapid Visco Analyser (RVA). (A). single transgenic lines expressing the HMW-GS subunits 1Ax1, 1Dx5 and 1Dy10. (B). transgenic lines expressing combinations of the 1Ax1, 1Dx5 and 1Dy10 HMW-GS transgenes. Temperature is shown as the solid colored lines. 